\title{
Operating Characteristics of Multiple Evaporators and Multiple Condensers Loop Heat Pipe with Polytetrafluoroethylene Wicks
}

\author{
Sho Okutani' ${ }^{1}$, Hosei Nagano¹, Shun Okazaki², Hiroyuki Ogawa'2, Hiroki Nagai ${ }^{3}$ \\ ${ }^{1}$ Department of Aerospace Engineering, Nagoya University, Nagoya, Japan \\ ${ }^{2}$ Japan Aerospace Exploration Agency, Sagamihara, Japan \\ ${ }^{3}$ Department of Aerospace Engineering, Tohoku University, Sendai, Japan \\ Email: nagano@nuae.nagoya-u.ac.jp
}

Received 16 December 2013; revised 16 January 2014; accepted 23 January 2014

Copyright (C) 2014 by authors and Scientific Research Publishing Inc.

This work is licensed under the Creative Commons Attribution International License (CC BY). http://creativecommons.org/licenses/by/4.0/

(c) (7) Open Access

\section{Abstract}

This paper presents fabrication and testing of a multiple-evaporator and multiple-condenser loop heat pipe (MLHP) with polytetrafluoroethylene (PTFE) porous media as wicks. The MLHP has two evaporators and two condensers in a loop heat pipe in order to adapt to various changes of thermal condition in spacecraft. The PTFE porous media was used as the primary wicks to reduce heat leak from evaporators to compensation chambers. The tests were conducted under an atmospheric condition. In the tests that heat loads are applied to both evaporators, the MLHP was stably operated as with a LHP with a single evaporator and a single condenser. The relation between the sink temperature and the thermal resistance was experimentally evaluated. In the test with the heat load to one evaporator, the heat transfer from the heated evaporator to the unheated evaporator was confirmed. In the heat load switching test, in which the heat load is switched from one evaporator to another evaporator repeatedly, the MLHP could be stably operated. The loop operation with the large temperature difference between the heat sinks was also tested. From this result, the stable operation of the MLHP in the various conditions was demonstrated. It was also found that a flow regulator which prevents the uncondensed vapor from the condensers is required at the inlet of the common liquid line when one condenser has higher temperature and cannot condense the vapor in it.

\section{Keywords}

Loop Heat Pipe; Multiple Evaporators; Multiple Condensers; Thermal Control; Two-Phase Heat

How to cite this paper: Okutani, S., Nagano, H., Okazaki, S., Ogawa, H. and Nagai, H. (2014) Operating Characteristics of Multiple Evaporators and Multiple Condensers Loop Heat Pipe with Polytetrafluoroethylene Wicks. Journal of Electronics Cooling and Thermal Control, 4, 22-32. http://dx.doi.org/10.4236/jectc.2014.41003 


\section{Transfer}

\section{Introduction}

As sophistication and diversification of recent space mission, the thermal requirements for spacecraft are getting stricter. Under such background, a heat transport device with no electric power, named loop heat pipe (LHP) is under development. LHPs are two phase heat transfer devices which utilize the capillary forces developed in porous media and latent heat at phase change of fluid [1] [2]. LHPs have been used for thermal control of spacecraft such as GLAS, SWIFT, and MAXI [3]-[5]. However, future space mission requires much more strict thermal control. For example, planetary probes and lunar rovers are exposed to the large changes of external thermal environment. The amount of heats generated from the instruments changes with the situation. Additionally, usable electric power for thermal control is limited. Therefore more functional thermal control device is required. This research focuses on multiple-evaporator and multiple-condenser loop heat pipes (MLHPs) which have multiple evaporators and condensers in a LHP. The concept of the MLHP has been proposed and several researches on the MLHP have been conducted. Bienert et al. [6] proposed the concept of the dual evaporators LHP, and the feasibility of the dual LHP was demonstrated with titanium wicks and water as the working fluid. Ku et al. [7] [8] have developed a miniature MLHP with titanium wicks and ammonia as the working fluid, and comprehensive test programs were executed in order to apply a miniature MLHP to ST-8 program. However, the researches on the MLHP are still limited, and complex behaviors in the MLHP have not been well cleared. As a result, the technology of the MLHP has not been demonstrated in orbit. The final goal of this study is to figure out operations and behaviors of the MLHP under various conditions, and to establish the detailed model of the MLHP in order to develop a high functional MLHP. In the past, authors have developed a single LHP with a PTFE wick and demonstrated a good performance of the LHP [9]. In this paper, a small MLHP with PTFE wicks was newly designed and fabricated, and basic performance of the MLHP was experimentally evaluated in an atmospheric condition. Firstly, the basic characteristics and advantages of the MLHP for spacecraft thermal control were explained. Secondly, the specification of the MLHP which was designed and fabricated, and test conditions were explained. Next, the test results of the MLHP including the heat loads applied to both evaporators, to only one evaporator, and switched from one evaporator to another evaporator were presented. Finally, the test result when the sink temperature on the condensers was different under a constant heat load was presented.

\section{Features and Principle of MLHP}

Figure 1 shows a schematic view of a MLHP. The MLHP consists of two evaporators, two condensers, vapor lines, liquid lines and a working fluid. The evaporators and the condensers are connected in parallel with vapor lines and liquid lines. Each evaporator has a reservoir, so called compensation chamber (CC) and pours wicks.

The principle of the MLHP is as follows; In the case that heat loads applied to both evaporators (Figure 1(a)), the vapor generated in each evaporator flows to the vapor lines and confluents at the common vapor line, then flows into each condenser. The working fluid is condensed in the condensers, converges at the common liquid line, and flows to each evaporator. The mass flow rate through each evaporator is determined by a value of heat load applied to each evaporator. Temperature of each CC is determined by the ambient and the sink temperatures, the flow rate of the returning liquid from the liquid lines, and heat leak from the evaporator. If the total pressure drop of the loop exceeds the maximum capillary forces generated in a wick, the vapor penetrates the wick from the evaporator to the $\mathrm{CC}$, then the operating temperature increases, and finally, exceeds the temperature limit.

In the case that the uneven heat loads are applied to each evaporator, for instance, the heat load to evaporator 1 (Evap. 1) is larger than that to evaporator 2 (Evap. 2), the CC at Evap. 1 side (CC1) is cooled and filled with cold returning liquid since the mass flow rate through Evap. 1 is larger than that through Evap. 2. In this case, the fluid in the CC at Evap. 2 side (CC2) is two-phase state, and the CC2 controls the operating temperature. When the heat load is applied to only one evaporator (e.g. Evap. 1) (Figure 1(b)), the flow direction of the working fluid in Evap. 2 is reverse (reverse flow) of the direction in the cases that heat loads applied to both 


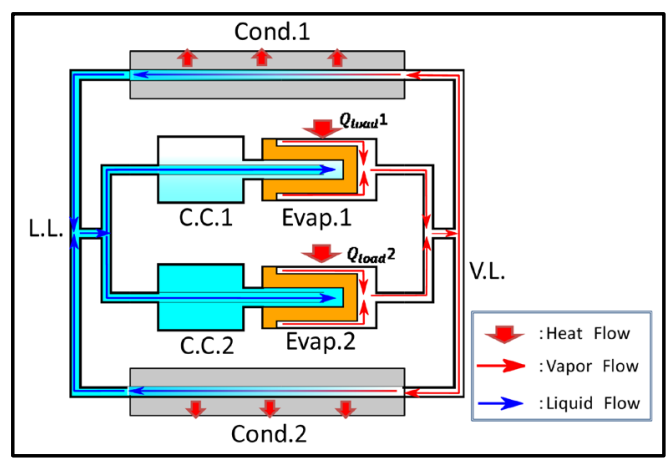

(a)

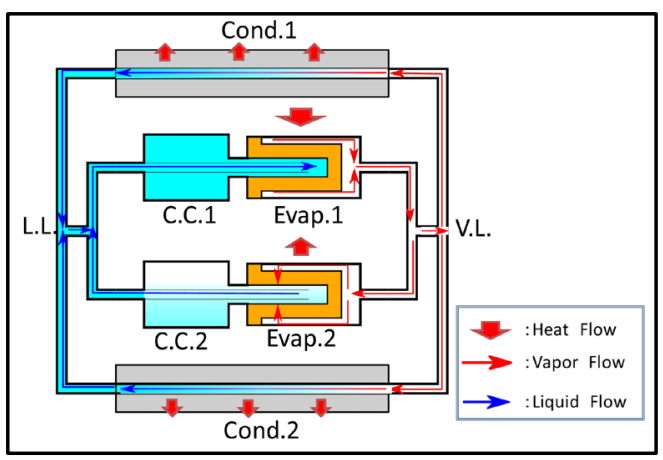

(b)

Figure 1. Schematic of a MLHP. (a) Heat loads to both evaporators; (b) Heat load to one evaporator.

evaporators (forward flow). The vapor generated in Evap. 1 is flows to the condensers through the vapor line. On the other hand, a part of the vapor flows into Evap. 2 through the vapor line, and the condensed in Evap. 2. The liquid flows into Evap. 1 through the liquid line. If the liquid from Evap. 2 has higher temperature than the returning liquid from the condensers, CC2 temperature is higher than that of CC1, and CC2 controls the operating temperature of the loop. If the total pressure drop of the loop exceeds the maximum capillary forces generated in the wick, however, the vapor penetrates the wick from Evap. 1 to CC1, then CC1 temperature becomes higher, and CC1 starts controlling the operating temperature of the loop.

Features and advantages of MLHPs are summarized as follows:

1) By having two evaporators, MLHPs can be used for cooling multiple heat sources or a heat source with a large thermal footprint.

2) By having two condensers, MLHPs can dissipate heats for two areas. For instance, in the case that one radiator is high-temperature and cannot condense the vapor in it, the other radiator can be used for dissipating heat.

3) Because of the heat transfers between the evaporators through the common vapor line, MLHPs can be used for keeping multiple instruments in a similar temperature. As a result, especially in a cold case, the electric power to maintain the instrument's temperature can be saved.

\section{Experiment System and Test Conditions}

\subsection{Experiment System}

The MLHP was designed by using mathematical model for a single evaporator LHP [10]-[12], on condition that both evaporators are heated and heat is transferred in forward direction, that is, the heat is transferred from each evaporator to the common vapor line, the condensers, and the common liquid line. To reduce the heat leak from the evaporators to the CCs and to lower the operating temperature, PTFE porous media is used as primary wicks which have lower thermal conductivity than traditional metal wicks [9]. Figure 2 illustrates 1) overview of the experimental MLHP which consisted of two parallel evaporators, two parallel condensers, a common vapor transport line and a common liquid return line, and 2) evaporator-CC section with temperature measurement points. The configurations of the MLHP are presented in Table 1. Each evaporator was made of stainless steel tubing with an outer diameter (O.D.) of $12 \mathrm{~mm}$ and a length of $70 \mathrm{~mm}$. Each CC was made of a stainless steel tube of $36 \mathrm{~mm}$ in O.D. $\times 45 \mathrm{~mm}$ in length. The vapor line and liquid line, each $770 \mathrm{~mm}$ long, were made of stainless steel tubes with O.D.s of $3.18 \mathrm{~mm}$, respectively. Each condenser was made of a stainless steel tube with an O.D. of $3.18 \mathrm{~mm}$ and length of $500 \mathrm{~mm}$. Pure acetone (99.5\%) is selected as a working fluid. The fluid inventory is determined as $60 \mathrm{cc}$. The size of the compensation chamber and the fluid inventory were decided from following procedure; Even in the cold case, that is, when no heat load is applied to the evaporator and the condenser sink temperature is at its minimum, the LHP is charged such that some liquid is left in the compensation chamber when the rest of the loop is completely flooded. The fluid inventory must satisfy the following relation under the cold case:

$$
M=\rho_{l, c}\left(V_{\text {loop }}+\beta V_{\mathrm{CC} 1}+V_{\mathrm{CC} 2}\right)+\rho_{v, c}\left\{(1-\beta) V_{\mathrm{CC} 1}\right\}
$$


Table 1. Configurations of the MLHP.

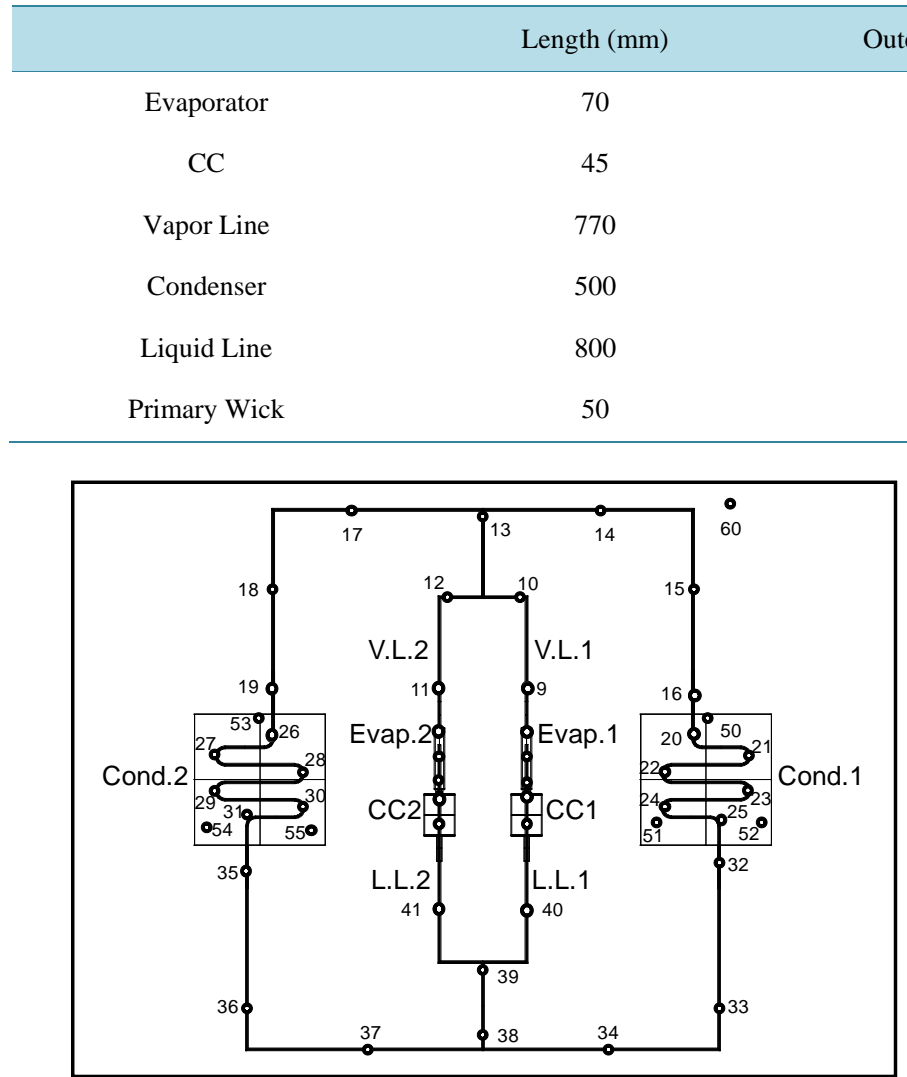

(a)

Outer Diameter (mm) Inner Diameter $(\mathrm{mm})$

$\begin{array}{cc}12 & 9.3 \\ 36 & 34 \\ 3.18 & 1.75 \\ 3.18 & 1.75 \\ 3.18 & 1.75 \\ 9.55 & 5\end{array}$

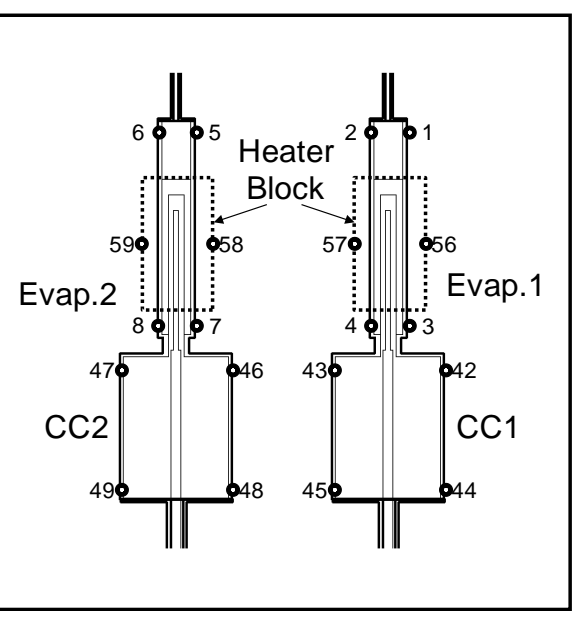

(b)

Figure 2. Experimental MLHP. (a) Overview; (b) Evaporator-CC section.

where $M$ is the mass of working fluid, $\rho_{l, c}$ and $\rho_{v, c}$ are liquid density and vapor density, respectively, of the working fluid at the minimum temperature, $V_{\text {loop }}$ is the loop total volume excluding the compensation chamber, $V_{\mathrm{CC}}$ is the compensation chamber volume, and $\beta$ is the fraction of compensation chamber volume occupied by the liquid.

Another requirement is that even in the hot case, that is, when a maximum heat load is applied to the evaporator and the condenser sink temperature is at its maximum, some vapor space is available in the compensation chamber when the condenser is fully utilized. The fluid inventory must satisfy the following relation under the hot case:

$$
M=\rho_{l, h}\left[V_{L L}+V_{p w}+(1-\alpha) V_{\mathrm{CC} 1}\right]+\rho_{v, h}\left(V_{g r}+V_{V L}+V_{\text {cond }}+\alpha V_{\mathrm{CC} 1}+V_{\mathrm{CC} 2}\right)
$$

where $\rho_{l, h}, \rho_{v, h}$ are liquid density and vapor density, respectively, of the working fluid at the maximum temperature, $V_{L L}$ is the volume of the liquid line, $V_{p w}$ is the void volume of the primary wick, $V_{g r}$ is the volume of the grooves, $V_{V L}$ is the volume of the vapor line, and $V_{\text {cond }}$ is the volume of the condenser lines, and $\alpha$ is the void fraction of compensation chamber volume.

In this study, the values of $\alpha$ and $\beta$ are determined to be about 0.1 . Once values of $\alpha$ and $\beta$ are determined, the compensation chamber volume and the fluid inventory can be calculated from the above equations. Finally, the fluid charge must be checked against the upper limit allowed by the loop. An upper limit exists because the loop must be able to contain all the liquid volume at the maximum non-operating temperature in order to prevent bursting due to the hydrostatic pressure. Thus the following constraint applies:

$$
M \leq \rho_{l, \max }\left(V_{\text {loop }}+V_{\mathrm{CC} 1}+V_{\mathrm{CC} 2}\right)
$$

where $\rho_{l, \max }$ is the liquid density at the maximum nonoperating temperature. From Equations (1) and (2), the 
volume of the CC, $V_{\mathrm{CC} 1}\left(=V_{\mathrm{CC} 2}=V_{\mathrm{CC}}\right)$ is determined as follows:

$$
V_{\mathrm{CC}}=\frac{\rho_{v, h}\left(V_{L L}+V_{p w}\right)+\rho_{v, h}\left(V_{g r}+V_{V L}+V_{\text {cond }}\right)-\rho_{l, c} V_{\text {loop }}}{\rho_{l, c}(\beta+1)+\rho_{v, c}(1-\beta)-\rho_{l, h}(2-\alpha)-\rho_{v, h} \alpha}
$$

A 200-gram aluminum heater blocks were attached to the evaporators to simulate the instrument mass. Four cartridge heaters capable of delivering $1 \mathrm{~W}$ to $200 \mathrm{~W}$ were inserted into each thermal mass to provide heat loads to the evaporators. 60 T-type thermocouples are used for measurement of temperature for the MLHP. The circles and numbers in Figure 2 mark the temperature measurement points and thermocouple numbers. The condenser tubes are connected to aluminum plates, which were attached to copper cold plates. Each condenser cold plate was cooled convectively by a separate chiller. The two chillers allowed temperatures of the two condenser plates to vary independently. The applied power was obtained from the multiplication of the measured voltage and measured current. A data acquisition system consisting of a data logger, a personal computer, and a screen monitor was used to collect and store temperature and power data every second. Forty $\mathrm{T}$ type thermocouples were used to monitor the temperatures. The accuracies of measurement for absolute temperature was $\pm 1^{\circ} \mathrm{C}$. Labview software was used for the command and control of the test conditions. The MLHP was set horizontally. The MLHP is insulated from environment during the tests. All tests were conducted under atmospheric conditions.

\subsection{Test Conditions}

Table 2 lists test conditions. Following four kinds of tests were conducted:

1) Test with heat loads to both evaporators to confirm the behavior of the MLHP. This test was conducted in the conditions that sink temperatures was varied from $10^{\circ} \mathrm{C}$ to $50^{\circ} \mathrm{C}$.

2) Test with heat load to one evaporator to confirm the heat transfer between the evaporators.

3) Test to examine the response to the switching the heat load from one evaporator to the other.

4) Test with sink temperature changes under the constant heat load to investigate the operation with the large temperature difference between the sinks.

\section{Test Results}

\subsection{Test Result of the Case 1}

In the test Case 1, the heat loads applied to both evaporators were increased in $5 \mathrm{~W}$ increments from $0 \mathrm{~W} / 0 \mathrm{~W}$ to $50 \mathrm{~W} / 50 \mathrm{~W}$ in the condition that the sinks temperature was kept constant. The temperature profile during test case 1 in the sinks temperature $20^{\circ} \mathrm{C} / 20^{\circ} \mathrm{C}$ is shown in Figure 3. Numbers in parentheses in Figure 3 correspond to the thermocouple numbers in Figure 2. The MLHP started 10 minutes after the heat loads of $5 \mathrm{~W} / 5 \mathrm{~W}$ were applied, and was stably operated until $40 \mathrm{~W} / 40 \mathrm{~W}$ was loaded. In the heat loads of $45 \mathrm{~W} / 45 \mathrm{~W}$, the CCs temperature began to rise, and in the heat loads of $50 \mathrm{~W} / 50 \mathrm{~W}$, the large temperature increasing were observed at the evaporators. This is because that the total pressure drop of the loop was over the maximum capillary forces of the wick, and the vapor penetrates the wick to the $\mathrm{CC}$ from the evaporator. There was the same tendency in the results of the sink temperatures from $10^{\circ} \mathrm{C} / 10^{\circ} \mathrm{C}$ to $40^{\circ} \mathrm{C} / 40^{\circ} \mathrm{C}$. In the case that the sinks temperature was kept at $50^{\circ} \mathrm{C} / 50^{\circ} \mathrm{C}$, however, because the vapor was not condensed completely in the condenser, and the temperature of the returning liquid was high, the CCs and evaporators temperatures became high.

\section{Table 2. Test conditions.}

\begin{tabular}{ccc}
\hline Case & Heat load to Evap. 1/Evap. $2(\mathrm{~W})$ & Sink temperature sink $1 / \operatorname{sink} 2\left({ }^{\circ} \mathrm{C}\right)$ \\
\hline 1 & $0 / 0,5 / 5,10 / 10,15 / 15,20 / 20,25 / 25,30 / 30,35 / 35,40 / 40,45 / 45,50 / 50$ & $10 / 10,20 / 20,30 / 30,40 / 40,50 / 50$ \\
2 & $0 / 0,5 / 0,10 / 0,15 / 0,20 / 0,25 / 0,30 / 0,35 / 0,40 / 0,45 / 0,50 / 0,55 / 0,60 / 0$ & $-10 /-10$ \\
3 & $0 / 0,25 / 25,50 / 0,0 / 50,50 / 0,0 / 50,25 / 25$ & $20 / 20$ \\
4 & $30 / 30$ & $-20 /-20,0 /-20,20 /-20,40 /-20,60 /-20,80 /-20$ \\
\hline
\end{tabular}




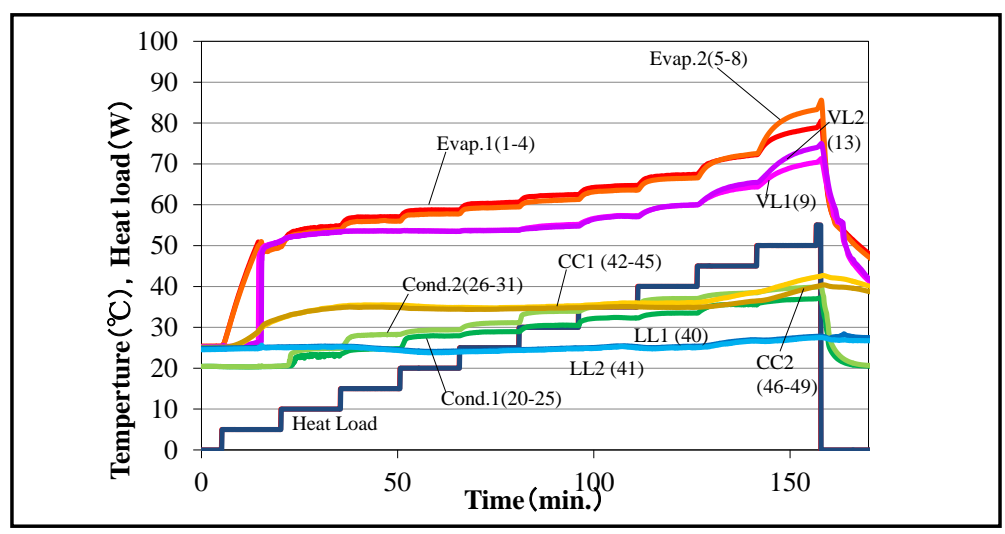

Figure 3. Temperature profile during test case 1.

From these results, the thermal resistance between the evaporator and the condenser $R_{\text {evap_cond }}$ is evaluated for each sink temperatures by Equation (5).

$$
R_{\text {evap_cond }}=\frac{\overline{T_{e c}}-\overline{T_{\text {cond }}}}{Q_{\text {load }}}
$$

where, $\overline{T_{e c}}$ is the average temperature of the evaporator casing (TC1-4) and $\overline{T_{\text {cond }}}$ is the average temperature of the condenser (TC20-31).

Figure 4 shows the thermal resistances for each sink temperature. Only Evap. 1 side was shown about the argument on thermal resistance, since the same tendency was also obtained at Evap. 2 side.

It is found that as the sink temperature becomes higher, the thermal resistance becomes smaller. In the case that the sink temperature was from $10^{\circ} \mathrm{C}$ to $40^{\circ} \mathrm{C}$, the thermal resistance becomes smaller as the heat loads become higher. This indicates that the operating temperature does not change comparatively with the heat loads. When the sink temperature was $40^{\circ} \mathrm{C}$, and the heat loads was $45 \mathrm{~W} / 45 \mathrm{~W}$, the thermal resistance takes the value of $0.58 \mathrm{~K} / \mathrm{W}$. In the case that the sink was $50^{\circ} \mathrm{C}$, and the heat loads were more than $20 \mathrm{~W} / 20 \mathrm{~W}$, the thermal resistance increased by rising of the operating temperature.

$R_{\text {evap_cond }}$ is divided into three parts and expressed by Equation (6).

$$
R_{\text {evap } \_ \text {cond }}=R_{\text {evap }}+R_{\text {vl }}+R_{\text {cond }}
$$

where, $R_{\text {evap }}$ is the thermal resistance of the evaporator. It is evaluated from the evaporator average temperature and the vapor line (TC9) inlet temperature by Equation (7).

$$
R_{\text {evap }}=\frac{\overline{T_{e c}}-T_{\text {v1_in }}}{Q_{\text {load }}}
$$

$R_{v l}$ is the thermal resistance of the vapor line. It is evaluated from the vapor line inlet temperature (TC9) and the vapor line outlet temperature (TC16) by the following equation;

$$
R_{v l}=\frac{T_{v l_{\text {_in }}}-T_{\mathrm{vl} \_ \text {out }}}{Q_{\text {load }}}
$$

$R_{\text {cond }}$ is the thermal resistance of the condenser. It is evaluated from the vapor line outlet temperature (TC16) and the condenser average temperature (TC20-25) by the following equation;

$$
R_{\text {cond }}=\frac{T_{\text {vl_out }}-\overline{T_{\text {cond }}}}{Q_{\text {load }}}
$$

Figure 5 shows $R_{\text {evap }}, R_{v l}$ and $R_{\text {cond }}$ as a function of the heat load in the case that sink temperatures were $10^{\circ} \mathrm{C} / 10^{\circ} \mathrm{C}$ and $40^{\circ} \mathrm{C} / 40^{\circ} \mathrm{C}$ respectively.

Figure 5(a) reveals that $R_{\text {cond }}$ is the largest in the case the sinks temperatures were $10^{\circ} \mathrm{C} / 10^{\circ} \mathrm{C}$, especially large for low heat loads. This is because the most part of the condensers is used for sub-cooling the condensed liquid. 


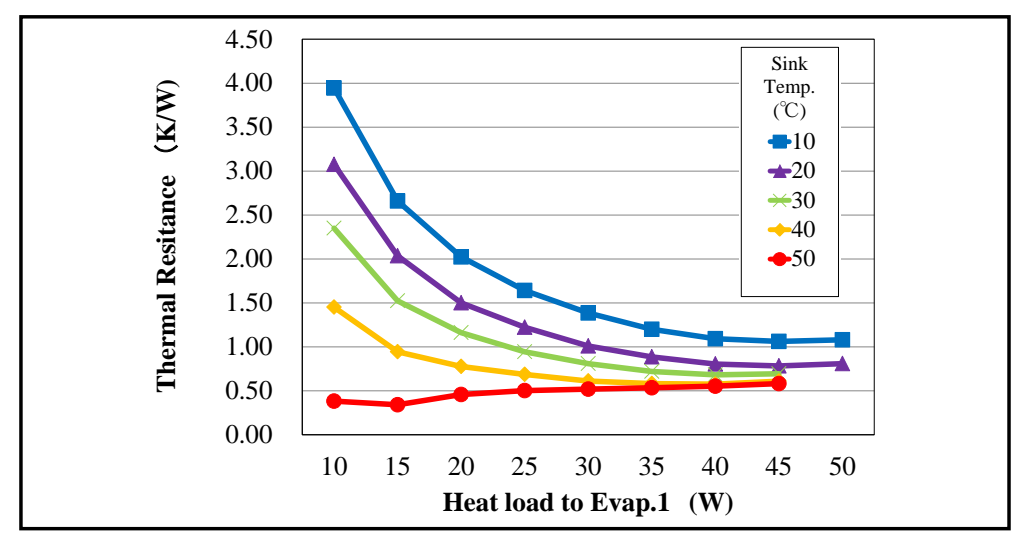

Figure 4. Thermal resistance for sink temperatures.

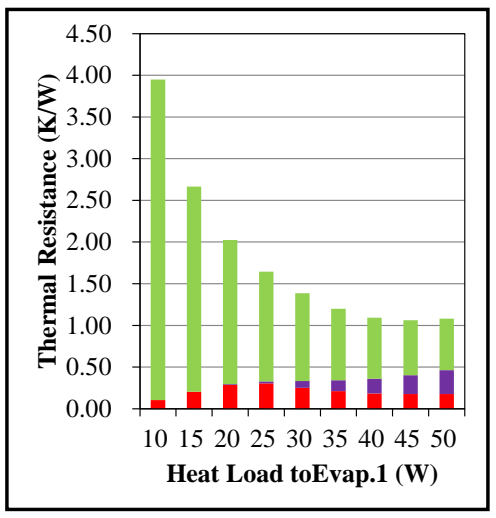

(a)

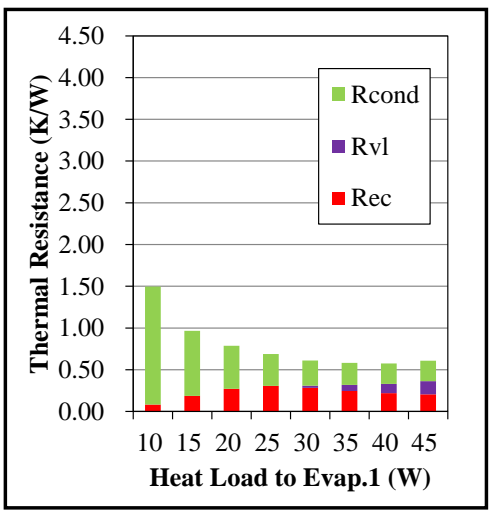

(b)

Figure 5. Thermal resistances. (a) Sink $10^{\circ} \mathrm{C} / 10^{\circ} \mathrm{C}$; (b) Sink $40^{\circ} \mathrm{C} / 40^{\circ} \mathrm{C}$.

Even when the heat loads were $50 \mathrm{~W} / 50 \mathrm{~W}$, the condensation finished at the first half of the condenser. For this reason, $R_{\text {cond }}$ becomes larger. In the case the sinks were $40^{\circ} \mathrm{C} / 40^{\circ} \mathrm{C}$, on the other hand, $R_{\text {cond }}$ becomes smaller. It is because the temperature difference between the evaporator and the condenser becomes smaller. In order to reduce the thermal resistance at lower sink temperature, it is required to shorten the condenser length or reduce thermal conductance between the condenser tube and condenser plates. For heat dissipation in space application, the thermal resistance is not necessarily important parameter since heat dissipation is conducted passively, and no electric power such as a fun is required. However, in order to keep instrument's temperature in a narrow range by reducing subcooling, it is required to introduce thermo-electric converter or heat exchange blocks between the vapor and the liquid lines. Therefore thermal design to reduce thermal resistance as a basic characteristic is required.

Next, the thermal resistance of the evaporator $R_{\text {evap }}$ and the thermal resistance of the vapor line $R_{v l}$ are considered. $R_{\text {evap }}$ and $R_{v l}$ at sink temperature of $30^{\circ} \mathrm{C} / 30^{\circ} \mathrm{C}$ are shown in Figure 6 .

The thermal resistance of the evaporator is valued between 0.1 and $0.3 \mathrm{~K} / \mathrm{W}$. When the heat loads were less than $25 \mathrm{~W} / 25 \mathrm{~W}, R_{\text {evap }}$ increased with the increasing of the heat loads. However, in the heat loads more than 30 $\mathrm{W} / 30 \mathrm{~W}, R_{\text {evap }}$ decreased with the increasing of the heat loads and $R_{v l}$ began to increase. From Figure 3, it is also found that the vapor line temperature rose when more than $30 \mathrm{~W} / 30 \mathrm{~W}$ was applied. Thus it is considered that the situation of the heat transfer in the evaporator changes in heat loads of between $25 \mathrm{~W} / 25 \mathrm{~W}$ and $30 \mathrm{~W} / 30 \mathrm{~W}$.

Figure 7 shows the temperatures of the evaporator casing (TC1-4), the vapor line inlet (TC9) and the vapor line confluence (TC13).

When the heat loads were from $10 \mathrm{~W} / 10 \mathrm{~W}$ to $25 \mathrm{~W} / 25 \mathrm{~W}$, the temperature of the vapor line inlet agrees with the temperature of the vapor line confluence. When the heat loads were more than $30 \mathrm{~W} / 30 \mathrm{~W}$, however, the temperature difference between the vapor line inlet and the confluence exists. This means that the saturated vapor was generated in the evaporator and super-heated in the vapor grooves. For this reason, more than $30 \mathrm{~W} / 30 \mathrm{~W}$, 


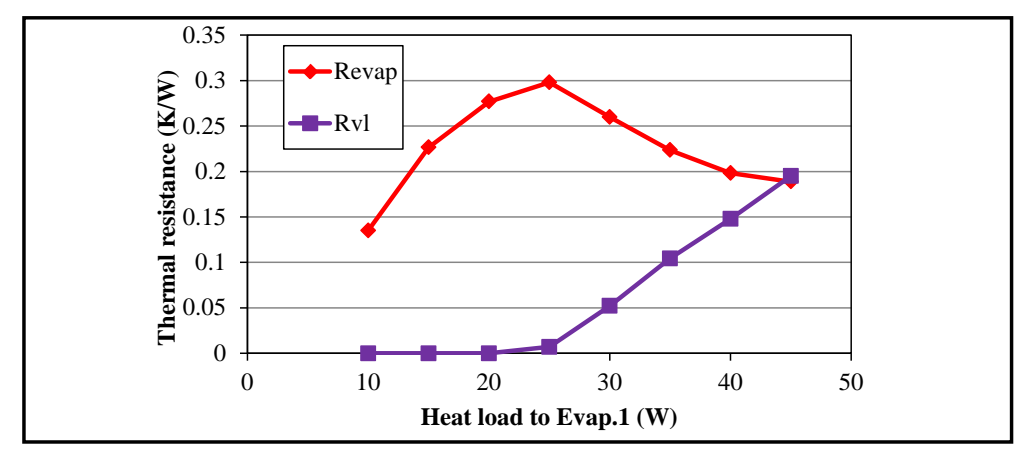

Figure 6. Thermal resistance of evaporator.

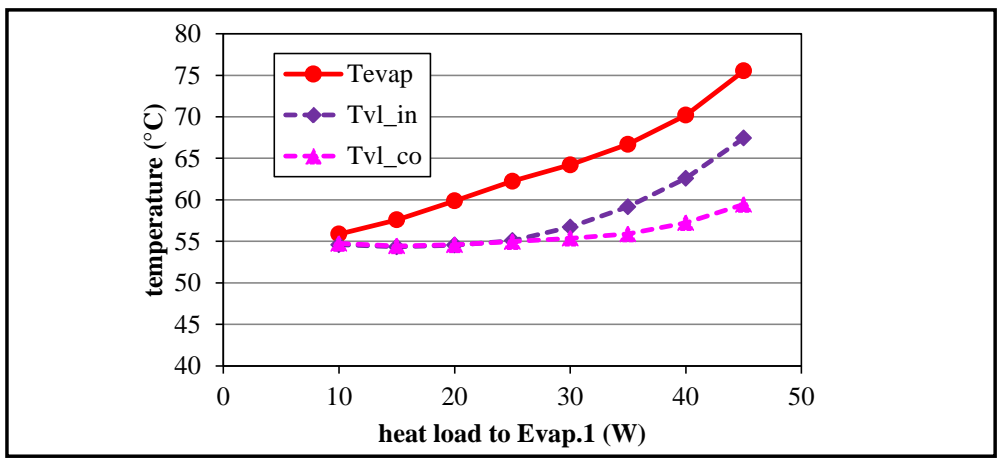

Figure 7. Temperatures for heat loads.

$R_{\text {evap }}$ decreases, and $R_{v l}$ increases.

The heat used for super-heat is evaluated by Equation (10).

$$
Q_{S H}=\dot{m} c_{p}\left(T_{v l_{-} i n}-T_{v l_{-} c o}\right)
$$

where, $T_{v l \_c o}$ is the temperature at the confluence of the vapor line. From this equation, the value was estimated as $0.8 \mathrm{~W}$ in $40 \mathrm{~W} / 40 \mathrm{~W}$ heat loads.

Based on the above-described results, the following thing is considered. For heat loads from $10 \mathrm{~W}$ to $25 \mathrm{~W}$, the thermal resistance in the evaporator increases with the expansion of vaporization zone at the wick outside. For the heat loads of more than $30 \mathrm{~W}$, the vapor super heating in the wick grooves becomes active by increasing of the thermal resistance from heating area to the evaporating zone. From this reason, $R_{\text {evap }}$ decreases and $R_{v l}$ increases.

\subsection{Test Result of the Case 2}

In the test case 2, the heat load was applied to Evap. 2 only. The temperature profile during test case 2 is shown in Figure 8. The heat load of $5 \mathrm{~W}$ was applied to Evap. 2, and then vapor flowed to Evap. 2 side vapor line after 8 minutes. This means the startup of the MLHP. As soon as the heat load of $10 \mathrm{~W}$ was applied to Evap. 2, an increase of the temperature of Evap. 1, which had no heat load, was observed. This is because the vapor generated in Evap. 2 flowed into Evap. 1 through the vapor line. It is demonstrated that the heat load to Evap. 2 is usable to warm up Evap. 1.

In the heat load of $0 \mathrm{~W} / 25 \mathrm{~W}$, CC2 had slightly higher temperature than CC1, and controlled the operating temperature. In the heat load of $0 \mathrm{~W} / 50 \mathrm{~W}$, CC2 temperature began to rise. In the heat load of $0 \mathrm{~W} / 55 \mathrm{~W}$, CC2 temperature exceeded CC1 temperature. Accordingly, it is considered that the vapor reaches to CC2 through the wick at this moment. This means that Evap. 2 reached the capillary limit. In the heat load of 0 W/W/60 W, Evap. 2 temperature reached to $100^{\circ} \mathrm{C}$, and the test was terminated. The amount of heat transferred to Evap. 1 from Evap. 2 was calculated by Equation (11).

$$
Q_{\text {evap }}=\left(\frac{1}{h_{\text {evap }} A}+\frac{\ln \left(d_{o} / d_{i}\right)}{2 \pi k L}\right)\left(\overline{T_{e c}}-T_{\text {vap }}\right)
$$




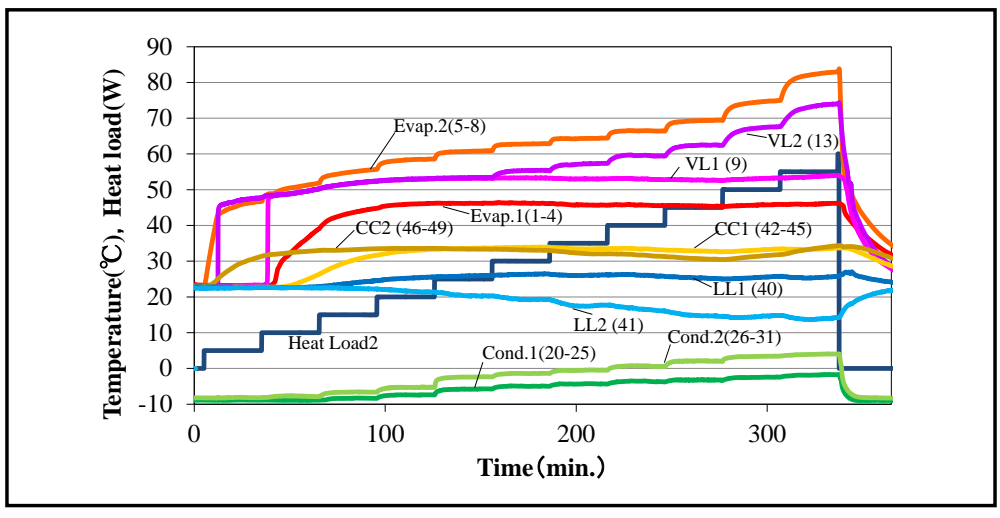

Figure 8. Temperature profile during test case 2.

where, $T_{\text {vap }}$ is the vapor temperature in the evaporator-in this calculation, the vapor line inlet temperature (TC10) is used. Assuming that the heat transfer coefficient in Evap. 1 is $100 \mathrm{~W} / \mathrm{m}^{2} \mathrm{~K}, Q_{\text {evap }}$ is estimated as $0.8 \mathrm{~W}$ in the heat load from $0 \mathrm{~W} / 20 \mathrm{~W}$ to $0 \mathrm{~W} / 50 \mathrm{~W}$. The reason for this small $Q_{\text {evap }}$ is that the heat dissipation to the ambient from Evap. 1 was restricted by the thermal insulation. It is possible to increase the amount of heat transferred between the evaporators by absorbing more heat from Evap. 1.

\subsection{Test Result of the Case 3}

In the test case 3, the heat loads to each evaporators were switched under the condition that total heat load to the MLHP was kept at $50 \mathrm{~W}$. The temperature profile during test case 3 is shown in Figure 9. At first, the heat loads of $25 \mathrm{~W} / 25 \mathrm{~W}$ were applied and the MLHP started up. Secondly, the heat loads was changed into $50 \mathrm{~W} / 0 \mathrm{~W}$ from $25 \mathrm{~W} / 25 \mathrm{~W}$. The temperature of Evap. 2 began to fall. However, it was stable at around $55^{\circ} \mathrm{C}$ because the vapor flowed into Evap. 2 from Evap. 1, and the vapor flow direction change was occurred with the change of the heat loads. In this time, steady temperatures of Evap. 1 and Evap. 2 were $79.4^{\circ} \mathrm{C}$ and $54.5^{\circ} \mathrm{C}$ respectively. Thirdly, the heat loads was changed into $0 \mathrm{~W} / 50 \mathrm{~W}$ from $50 \mathrm{~W} / 0 \mathrm{~W}$. Then the flow direction of the working fluid in the evaporators was passively changed, namely, became forward flow in Evap. 2 and reverse flow in Evap. 1.

When the heat load is applied to one evaporator, the CC of the evaporator with no heat load controls the operating temperature of the loop, and it is passively switched with changing of the heat loads. When the heat loads change to $25 \mathrm{~W} / 25 \mathrm{~W}$ again, it is confirmed that the flow direction switches to forward.

In this way, when the heat loads was largely changed, the state of inner flow changed passively and the MLHP could be operated stably.

\subsection{Test Result of the Case 4}

In the test case 4, the heat loads to both evaporators were kept at $30 \mathrm{~W} / 30 \mathrm{~W}$, condenser 1 sink temperature was raised from $-20^{\circ} \mathrm{C}$ to $80^{\circ} \mathrm{C}$ at hourly intervals, while condenser 2 sink temperature was kept at $-20^{\circ} \mathrm{C}$. The temperature profile during test case 4 is shown in Figure 10. The steady temperature of each part of the MLHP when the sink temperatures are $-20^{\circ} \mathrm{C} /-20^{\circ} \mathrm{C}, 40^{\circ} \mathrm{C} /-20^{\circ} \mathrm{C}$ and $80^{\circ} \mathrm{C} /-20^{\circ} \mathrm{C}$ are shown in Figure 11 . When the sink temperatures were $-20^{\circ} \mathrm{C} /-20^{\circ} \mathrm{C}$, the MLHP was operated stably (Figure $11(\mathrm{a})$ ). The operating temperature stayed about the same when the sink temperatures were less than $+20^{\circ} \mathrm{C} /-20^{\circ} \mathrm{C}$ as shown in Figure 10 . When sink1 temperature was raised to $+40^{\circ} \mathrm{C}$, however, the temperatures of the both evaporators and the both condensers began to rise (Figure 11(b)). It is considered that the working fluid through condenser 1 was not condensed completely and condensed in the liquid line by meeting the sub-cooled liquid from condenser 2 . When sink1 temperature was raised to $+80^{\circ} \mathrm{C}$, it seems that the vapor reached the liquid line outlet, that is, the vaper was condensed from the liquid line to the CC. However the MLHP could keep operating by releasing heats to the ambient from the liquid line and the CCs (Figure 11(c)). In the case the sink temperature is high, to prevent the increasing of the operating temperature, a flow regulator which prevents the vapor to reach the CCs will be required. 


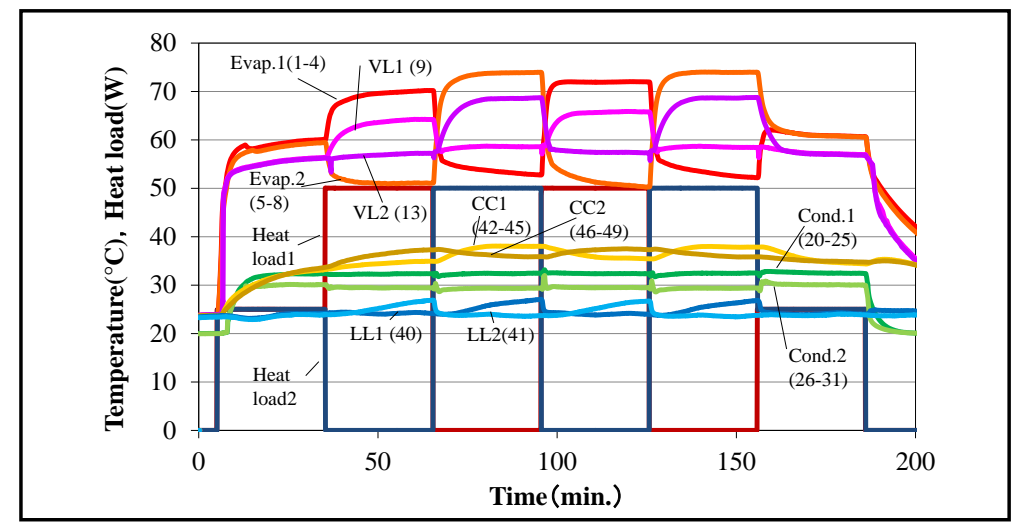

Figure 9. Temperature profile during test case 3.

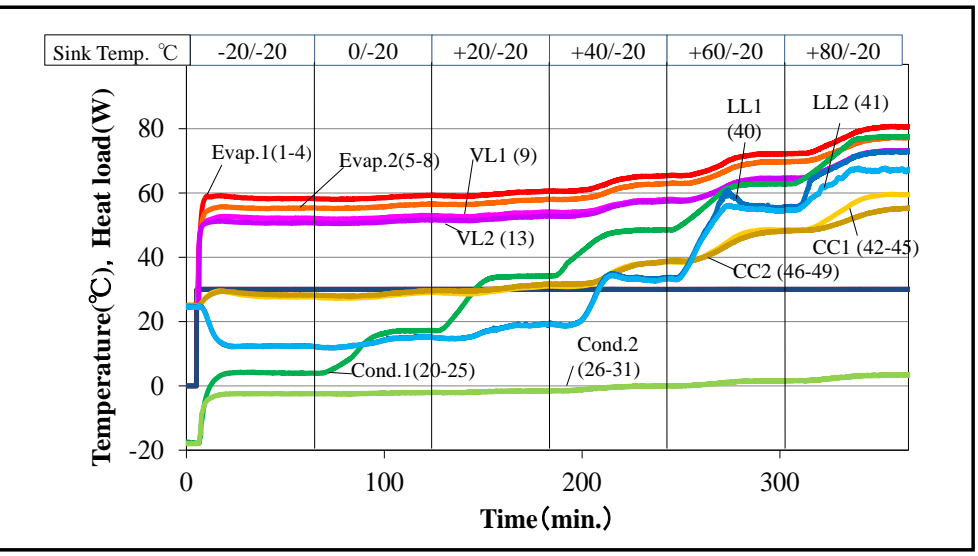

Figure 10. Temperature profile during test case 4.

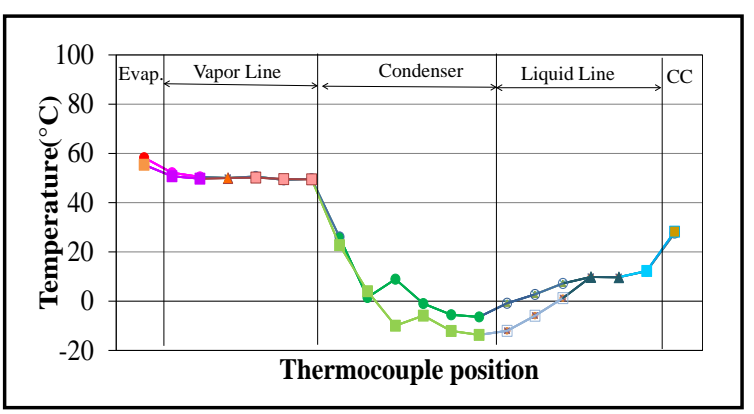

(a)

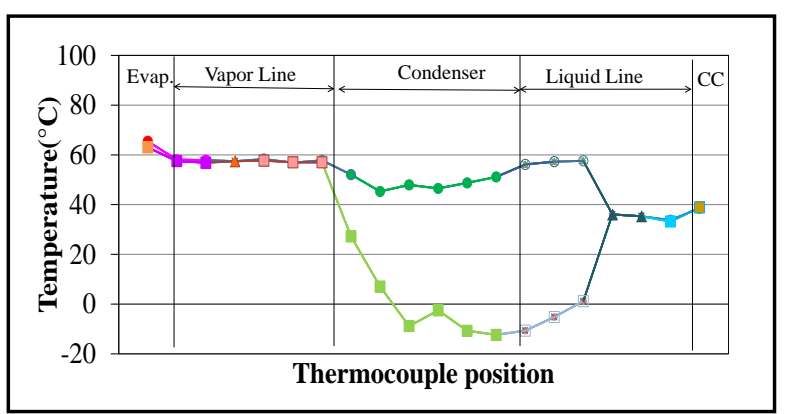

(b)

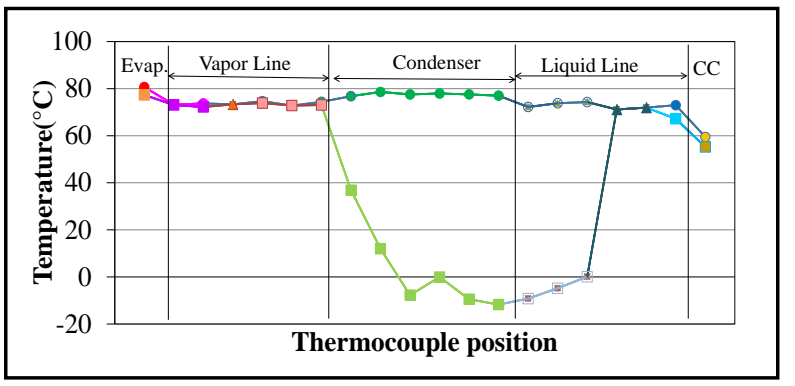

(c)

Figure 11. Steady temperatures. (a) Sink: $-20^{\circ} \mathrm{C} /-20^{\circ} \mathrm{C}$; (b) Sink: $+40^{\circ} \mathrm{C} /-20^{\circ} \mathrm{C}$; (c) Sink: $+80^{\circ} \mathrm{C} /-20^{\circ} \mathrm{C}$. 


\section{Conclusions}

The MLHP with PTFE wicks was newly fabricated and tested. In the tests that heat loads are applied to both evaporators, the MLHP was stably operated up to $40 \mathrm{~W} / 40 \mathrm{~W}$. The relation between the thermal resistance and the sink temperature was also cleared. In the test with heat load to one evaporator, the MLHP was stably operated up to $0 \mathrm{~W} / 50 \mathrm{~W}$, and the heat transfer between the evaporators was confirmed. In the heat load switching test, the MLHP could stably be operated. The operation with the large temperature difference between the heat sinks was tested. From this result, it was shown that retuned liquid or vapor from the condenser with higher temperature increased the operating temperature of the loop. It was also found that a flow regulator which prevents the uncondensed vapor from the condensers is required at the inlet of the common liquid line.

Hereafter, solving these problems, improvements of the steady state model, thermal vacuum tests will be conducted.

\section{References}

[1] Ku, J. (1999) Operating Characteristics of Loop Heat Pipes. Proceedings of the 29th International Conference on Environmental Systems, Paper No.1999-01-2007.

[2] Maydanik, Y.F. (2005) Review Loop Heat Pipes. Applied Thermal Engineering, 25, 635-657. http://dx.doi.org/10.1016/j.applthermaleng.2004.07.010

[3] Baker, C. and Grob, E. (2001) System Accommodation of Propylene Loop Heat Pipes for the Geoscience Laser Altimeter System (GLAS) Instrument. Proceedings of the 31st International Conference on Environmental Systems, SAE Paper No. 2001-01-2263.

[4] Choi, M. (2004) Thermal Vacuum/Balance Test Results of Swift BAT with Loop Heat Pipe Thermal System. Proceedings of the 2nd IECEC, AIAA Paper No. 2004-5683.

[5] Nagai, H. and Ueno, S. (2005) Performance Evaluation of Doublecondenser Loop Heat Pipe onboard Monitor of All-Sky X-Ray Image (MAXI) in Thermal Vacuum Testing. Proceedings of the 35th International Conference on Environmental Systems, SAE Paper No. 2005-01-2939.

[6] Bienert, W.B., Wolf, D.A., Nikitkin, M.N., Maydanik, Y.F., Fershtater, Y., Vershinin, S. and Gottschlich, J.M. (1997) The Proof-Of-Feasibility of Multiple Evaporator Loop Heat Pipes. Proceedings of the Sixth European Symposium on Space Environmental Control Systems, 393-398.

[7] Ku, J., Ottenstein, L., Douglas, D., Pauken, M. and Birur, G. (2005) Miniature Loop Heat Pipe with Multiple Evaporators for Thermal Control of Small Spacecraft. Government Microcircuit Applications and Critical Technology Conference, Paper No.183.

[8] Nagano, H. and Ku, J. (2007) Capillary Limit of a Multiple-Evaporator and Multiple-Condenser Miniature Loop Heat Pipe. Journal of Thermophysics and Heat Transfer, 21, 694-701. http://dx.doi.org/10.2514/1.26151

[9] Nagano, H., Fukuyoshi, F., Ogawa, H. and Nagai, H. (2011) Development of an Experimental Small Loop Heat Pipe with Polytetrafluoroethylene Wicks. Journal of Thermophysics and Heat Transfer, 25, 547-552. http://dx.doi.org/10.2514/1.T3614

[10] Nagano, H., Fukuyoshi, F., Nagai, H. and Ogawa, H. (2008) Study on Thermal Characteristics of a Small Loop Heat Pipe. Journal of Thermal Science and Technology, 3, 355-367. http://dx.doi.org/10.1299/jtst.3.355

[11] Nishikawara, M., Nagano, H. and Kaya, T. (2013) Transient Thermo-Fluid Modeling of Loop Heat Pipes and Experimental Validation. Journal of Thermophysics and Heat Transfer, 27, 641-647. http://dx.doi.org/10.2514/1.T3888

[12] Kaya, T. and Hoang, T.T. (1999) Mathematical Modeling of Loop Heat Pipes and Experimental Validation. Journal of Thermophysics and Heat Transfer, 13, 314-320. http://dx.doi.org/10.2514/2.6461 